SHORT COMMUNICATION

\title{
Apparent Competition Through Facilitation between Melanoides tuberculata and Biomphalaria glabrata and the Control of Schistosomiasis
}

\author{
Alexandre Giovanelli, Marcus Vinicius Vieira*, Cesar Luiz Pinto Ayres Coelho da Silva/ ${ }^{+}$ \\ Departamento de Biologia, Instituto Oswaldo Cruz-Fiocruz, Av. Brasil 4365, 21045-900 Rio de Janeiro, RJ, Brasil *Laboratório \\ de Vertebrados, Departamento de Ecologia, Universidade Federal do Rio de Janeiro, Rio de Janeiro, RJ, Brasil
}

\begin{abstract}
Interactions between two species that result in reduced growth rates for both and extinction of one of the species are generally considered cases of asymmetric interspecific competition. Exploitative or interference competition is the usual mechanism invoked. Here we describe another mechanism producing the same result, named apparent competition through facilitation (ACF), observed between Melanoides tuberculata and Biomphalaria glabrata populations. The superior competitor actually gives some benefit to the other species, whose population becomes unstable with progressively increasing oscillations, leading to extinction. A model of ACF using difference equations suggests initial dynamics distinct from traditional interspecific competition. The dynamics of two freshwater snails in the field and in laboratory experiments suggest $A C F$, and these relations should be considered in studies of schistosomiasis control. ACF could occur in natural populations, but might have gone undetected because the final result is similar to traditional interspecific competition.
\end{abstract}

Key words: apparent competition - population interactions - Biomphalaria glabrata - Melanoides tuberculata schistosomiasis control

Competition is traditionally viewed as a negative interaction because it reduces survivorship, growth or reproduction of the individuals concerned (Begon et al. 1996). In many circumstances, it is asymmetric leading to extinction of inferior competitors. In others, the negative effect of one species on another does not result from depletion of resources or a direct negative effect. Thus, in apparent competition (Holt 1977) or competition for enemyfree space (Jeffries \& Lawton 1984), two species are prey of a common predator and the increase in abundance of one leads to an increase in abundance of the predator. The predator exerts the negative effect on the survivorship of the other prey (Holt 1977, Jeffries \& Lawton 1984). One species of prey affects survivorship of the other negatively, but only indirectly, mediated by predation. Nevertheless, the interaction is still considered competition because the result is one species affecting the other negatively.

Here in we stretch the concept of apparent competition to include facilitation as another mechanism leading to a negative association between the abundance of two species, hereafter named apparent competition through facilitation (ACF). A simple scenario would be of two species that require similar resources and that are constantly

${ }^{+}$Corresponding author. Fax:+55-21-2560.6474. E-mail: cesarcs@ioc.fiocruz.br

Recevied 10 September 2002

Accepted 5 December 2002 colonizing or invading areas. Species A arrives first, and is common and widespread when species B arrives. After that, the abundance of A reduces or A goes extinct. Apparently, it is just one more case of competition for resources, however, right after the arrival of the late invader, the abundance of the species A increases. Species B actually gives some initial benefit to the other species, producing vital nutrients or a substance that stimulates growth. The result is a sudden increase in growth rates of species A. This benefit could be just a waste product or another substance produced by one species independently of the presence of the other. Increasing growth rates tend to destabilize populations, increasing oscillations, producing chaotic dynamics (May 1974), or leading to extinction (review in Soulé 1987). Thus, in a short time the population of species A becomes unstable with progressively increasing oscillations, and quickly goes extinct. The final result appears as interspecific competition because survivorship, growth or reproduction of the individuals concerned is reduced. However, the effect of species B on the other species is initially positive.

Some cases of reputed interspecific competition may actually be cases of ACF. At least in four studies of interspecific competition in freshwater snails, the inferior competitor initially increased in abundance when raised with the superior competition (Santos et al. 1989, Gomez et al. 1990, Stryker et al. 1991, Giovanelli et al. 2002). ACF is more likely in combinations of organisms and environment producing high intrinsic rates of natural increase. Natural candidates are organisms with short generation length and high fecundity in environments of initial and intermediate stages of succession, and in environments constantly being recolonized. 
The scenario portrayed previously was observed in a field study of two populations of Biomphalaria glabrata and Melanoides tuberculata in the municipality of Sumidouro, State of Rio de Janeiro, Brazil (22 ${ }^{\circ} 02^{\prime} 59^{\prime \prime} \mathrm{S}$, $\left.42^{\circ} 40^{\prime} 29^{\prime \prime} \mathrm{W}\right)$. The first snail, B. glabrata, is the intermediate host of trematode Schistosoma mansoni, which causes shistosomiasis in humans. The second, $M$. tuberculata, is originally from Africa, but it was accidentally introduced in the West Indies and Venezuela and used as biological control of $B$. glabrata (Pointier et al. 1991, Pointier \& Guyard 1992, Schlegel et al. 1997). In Brazil, the introduction was more likely an accident, a byproduct of introductions of aquatic plants and fish for fisheries (Vaz et al. 1986). The population of B. glabrata in an irrigation channel in Sumidouro has been monitored from May 1995 to September 1999. Periodic oscillations related to precipitation occurred until July 1997. In August 1997, right before the first individual of $M$. tuberculata was detected, the population of B. glabrata had one of its longest periods of sustained growth, reaching one of its highest densities (Giovanelli 2000). Densities declined abruptly after this period, reaching its lowest densities until September 1999. In a laboratory study of $M$. tuberculata and B. glabrata collected in Sumidouro, the fecundity of $B$. glabrata increased when raised with $M$. tuberculata (Giovanelli et al. 2002). This apparent contradiction suggests the occurrence of ACF.

We used the discrete model of May (1974) to simulate the dynamics of two species in a situation of ACF, classic exploitative competition, and without interaction between the two species. In the model of May (1974), interspecific competition was created by a negative interaction coefficient, $-\alpha_{12}$, representing the net effect of species 2 on 1 . We modeled ACF simply by making $\alpha_{12}$ positive:

$N_{1}(t+1)=N_{1}(t) \exp \left\{r_{1}\left[K_{1}-\alpha_{11} N_{l}(t)+\alpha_{12} N_{2}(t)\right] / K_{1}\right\}$ $N_{2}(t+1)=N_{2}(t) \exp \left\{r_{2}\left[K_{2}-\alpha_{21} N_{1}(t)-\alpha_{22} N_{2}(t)\right] / K_{2}\right\}$

To simulate the dynamics of the two snails in ACF, we used realistic values for the parameters of the model (Table). These values are similar to the observed in laboratory studies of M. tuberculata (Pointier et al. 1991) and B. glabrata (Pointier et al. 1991, Giovanelli 2000). Densities of $M$. tuberculata in the field were always higher than densities of Biomphalaria (Pointier 1993, Freitas \& Santos 1995).

The projected dynamics of ACF suggests extinction of $B$. glabrata after 26 generations, which could happen in less than three years in the case of B. glabrata (Fig. 1A). Before going extinct, the population of B. glabrata reached densities much higher than its carrying capacity. If $M$. tuberculata had no effect on B. glabrata $\left(\alpha_{12}=0\right)$, the two populations stabilize and $B$. glabrata reaches its carrying capacity after a few generations (Fig 1B).

Traditional interspecific competition also was simulated using May (1974) original model with all interaction coefficients negative. M. tuberculata was assumed to have a greater impact on B. glabrata than vice-versa, using $-\alpha_{12}=0.3$ and $-\alpha_{21}=0.2$. M. tuberculata reaches carrying capacity and B. glabrata goes extinct after 30 generations (Fig. 1C). Thus, B. glabrata takes a little longer to go extinct in interspecific than in ACF (Fig. 1A).
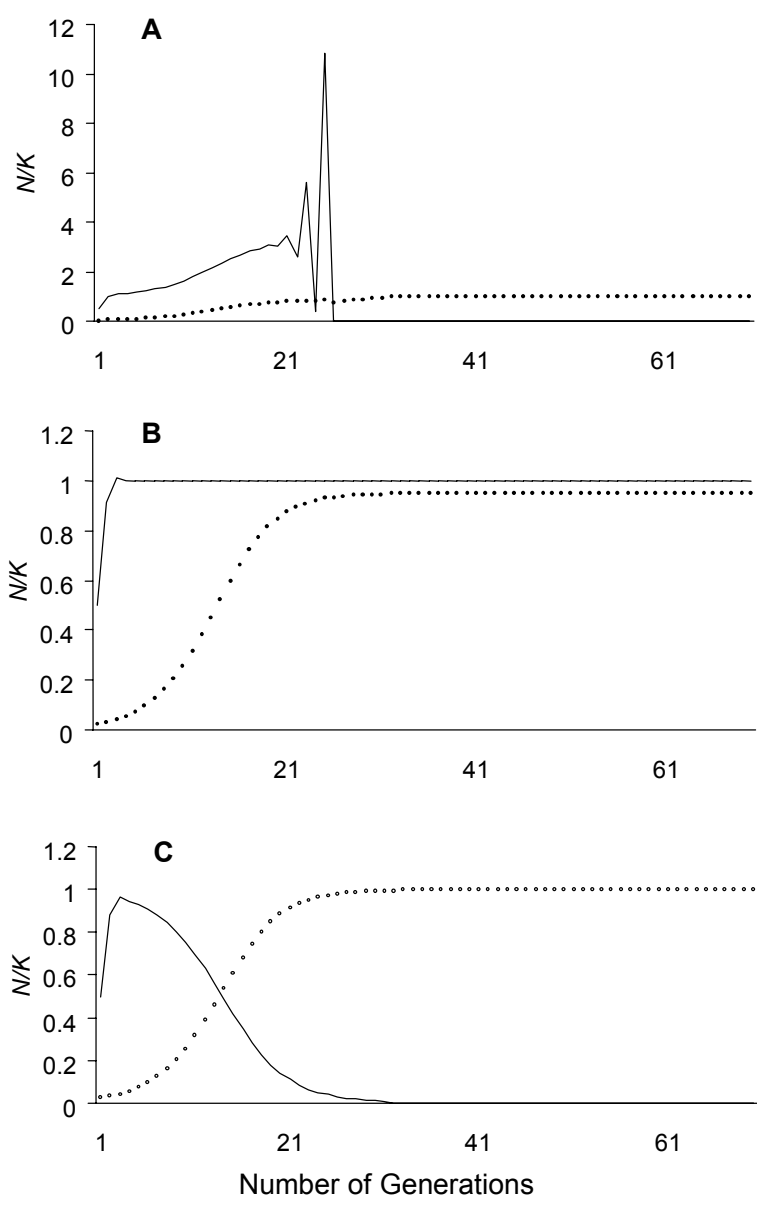

B. glabrata $/ k_{1} \quad$ …... M. tuberculata $/ k_{2}$

$N$ : population size; $K$ : carrying capacity

Fig. 1: projected dynamics of two snails in three situations where the effect of Melanoides tuberculata on Biomphalaria glabrata was positive $\left(\mathrm{A},+\alpha_{12}=0.7\right)$, absent $\left(\mathrm{B}, \alpha_{12}=0\right)$, and negative $(\mathrm{C}$, $\alpha_{12}=0.3$ ). The effect of B. glabrata on M. tuberculata was always negative $\left(-\alpha_{21}=0.2\right)$. A population was considered extinct when $N$ $<1$.

In the model of ACF presented, low to moderate growth rates $(r<1)$ produces stable dynamics. Above this threshold, increasing growth rates produce oscillations of increasing magnitude, resulting in chaotic dynamics of the inferior competitor, and eventually its extinction (Fig. 2). Increasing the positive effect $\left(+\alpha_{12}\right)$ also produces increasing oscillations and possibly extinction of the inferior competitor. Therefore, even when growth rates are low extinction of the inferior competitor is possible if the positive effect is high. In the specific case of B. glabrata, the number of generations necessary for extinction may be lower if environmental factors are considered. For example, precipitation has a marked effect on populations of Biomphalaria (Loreau \& Baluku 1987, Baptista \& Jurberg 1993, Belot et al. 1993).

The occurrence of ACF in natural populations is difficult to evaluate at the moment based only on literature 


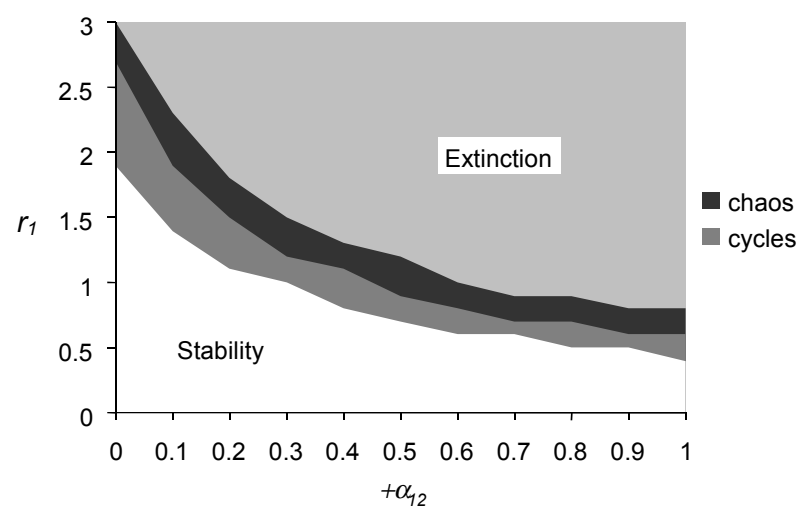

Fig. 2: dynamics of an inferior competitor for different combinations of intrinsic rate of natural increase $\left(r_{1}\right)$ and intensity of positive interaction $\left(+\alpha_{12}\right)$. The effect of the inferior competitor on the other species was always negative $\left(-\alpha_{21}=0.2\right)$. A population was considered extinct when $N<1$.

\section{TABLE}

Values used in the simulation of apparent competition through facilitation between two snails

\begin{tabular}{llllllll}
\hline $\begin{array}{l}\text { Biomphalaria glabrata } \\
\left(N_{1}\right)\end{array}$ & \multicolumn{4}{l}{$\begin{array}{l}\text { Melanoides tuberculata } \\
\left(N_{2}\right)\end{array}$} \\
\hline$r_{1}$ & $K_{1}$ & $-\alpha_{11}$ & $+\alpha_{12}$ & $r_{2}$ & $K_{2}$ & $-\alpha_{22}$ & $-\alpha_{21}$ \\
1.2 & 100 & 1 & 0.7 & 0.3 & 400 & 1 & 0.2 \\
\hline
\end{tabular}

$\alpha$ : interaction coefficient; $K$ : carrying capacity; $N$ : population; r: observed growth rate

review, because the final result is similar to traditional interspecific competition. However, ACF leads to a characteristic dynamics after the appearance of the late invader, the species that creates facilitation. The abundance of the established species increases as well as its oscillations, possibly leading to its extinction. Studies of species interactions must consider this possibility, especially when extinction of a previously established species occurs after the invasion of another. The bottom message of ACF is that an initial positive effect might ultimately be negative for a population. Actions of biological control of schistosomiasis should consider population interactions such as ACF.

\section{REFERENCES}

Baptista DF, Jurberg P 1993. Factors conditioning the habitat and the density of Biomphalaria tenagophila (Orbigny, 1853) in an isolated schistosomiasis focus in Rio de Janeiro city. Mem Inst Oswaldo Cruz 88: 457-464.

Begon M, Harper J, Townsend C 1996. Ecology: Individuals, Populations and Communities, 3rd ed., Blackwell Science, Oxford, $1068 \mathrm{pp}$.

Belot J, Geerts S, Diouf M 1993. Observations on the population dynamics of snail hosts for schistosomes in the Delta of the Senegal River Basin. J Mol Studies 59: 7-13.
Freitas JR, Santos MBL 1995. Current advances on the study of snail-snail interactions, with special emphasis on competition process. Mem Inst Oswaldo Cruz 90: 261-269.

Giovanelli A 2000. Competição entre os Moluscos Gastrópodos Melanoides tuberculata (Muller, 1774) e Biomphalaria glabrata (Say, 1818), Hospedeiro Intermediário do Schistosoma mansoni, unpublished MSc Thesis, Universidade Federal do Rio de Janeiro, Rio de Janeiro 100 pp.

Giovanelli A, Vieira MV, Coelho da Silva CLPA 2002. Interaction between the intermediate host of schistosomiasis in Brazil Biomphalaria glabrata (Planorbidae) and a possible competitor Melanoides tuberculata (Thiaridae): I. Laboratory experiments. Mem Inst Oswaldo Cruz 90: 261-269.

Gomez JD, Vargas M, Malek EA 1990. Biological control of Biomphalaria glabrata by Thiara granifera under laboratory conditions. Trop Med Parasitol 41: 43-45.

Holt RD 1977. Predation, apparent competition and the structure of prey communities. Theor Pop Biol 12: 197-229.

Jeffries MJ, Lawton JH 1984. Enemy-free space and the structure of ecological communities. Biol J Linnean Society 23: 269-286.

Loreau M, Baluku B 1987. Growth and demography of populations of Biomphalaria pfeifferi (Gastropoda, Planorbidae) in the laboratory. J Mol Studies 53: 171-177.

May RM 1974. Biological populations with nonoverlapping generations: stable points, stable cycles, and chaos. Science 186: 645-647.

Pointier JP 1993. The introduction of Melanoides tuberculata (Mollusca:Thiaridae) to the island of Saint Lucia (West Indies) and its role in the decline of Biomphalaria glabrata, the snail intermediate hosts of Schistosoma mansoni. Acta Trop 54: 13-18.

Pointier JP, Guyard A 1992. Biological control of the snail intermediate hosts of Schistosoma mansoni in Martinique, French West Indies. Trop Med Parasitol 43: 98-101.

Pointier JP, Balzan C, Chrosciechowski P, Incani RN 1991. Limiting factors in biological control of the snail intermediate hosts of Schistosoma mansoni in Venezuela. J Med \& Appl Malacol 3: 53-67.

Pointier JP, Toffart JL, Lefèvre M 1991. Life tables of freshwater snails of the genus Biomphalaria (B. glabrata, $B$. alexandrina, B. straminea) and of one of its competitors Melanoides tuberculata under laboratory conditions. Malacologia 33: 43-54.

Santos MB, Freitas JR, Alves ES, Rocha LA 1989. Competitive behavior of Biomphalaria glabrata and Biomphalaria tenagophila - Laboratory studies. Mem Inst Oswaldo Cruz 84: 156-178.

Schlegel L, Pointier JP, Petitjean-Roget V, Nadeau Y, Blateau A, Mansuy JM 1997. Le contrôle de la schistosomose intestinale de l'île de la Martinique. Parasite 4: 217-225.

Soulé M E 1987. Viable Populations for Conservation, Cambridge University Press, Cambridge, 189 pp.

Stryker GA, Koech DK Loker ES 1991. Growth of Biomphalaria glabrata populations in the presence of the ampullariid snails Pila orata, Lanistes carinatus and Marisa cornuarietis. Acta Trop 49: 137-147.

Vaz JF, Teles HM, Correa MA, Leite SP 1986. Ocorrência no Brasil de Thiara (Melanoides) tuberculata (O.F. Muller, 1774) (Gastropoda, Prosobranchia), the 1st intermediate host of Clonorchis sinensis (Cobbold, 1875) (Trematoda, Plathyhelmintes). Rev Saúde Públ 20: 318-322. 